\title{
Biomassa e atividade microbiana do solo sob pastagem em sistemas de monocultura e silvipastoril
}

\section{Soil microbial biomass and activity under pasture monoculture and silvopastoral systems}

\author{
Gynna Silva Azar ${ }^{1}$; Ademir Sérgio Ferreira de Araújoº ${ }^{2 *}$ Maria Elizabeth de Oliveira ${ }^{3}$; \\ Danielle Maria Machado Ribeiro Azevêdo ${ }^{4}$
}

\section{Resumo}

A biomassa microbiana é um importante componente do solo que contribui para manutenção do ecossistema de pastagens, principalmente em solos tropicais. Neste sentido, o objetivo do trabalho foi avaliar a biomassa e atividade microbiana do solo sob pastagem em sistemas de monocultura de pasto de Brachiaria brizantha cv. Marandu, e em sistema silvipastoril formado por pasto e coqueiros (Cocos nucifera). O experimento foi conduzido em 2009, no período de maio a novembro de 2009 no Campo Experimental da Embrapa Meio-Norte em Parnaíba-PI. Avaliou-se a fertilidade do solo, o carbono orgânico $\left(\mathrm{C}_{\mathrm{org}}\right)$, o carbono da biomassa microbiana $\left(\mathrm{C}_{\text {mic }}\right)$, a respiração do solo $\left(\mathrm{CO}_{2}\right)$, e a atividade decompositora das bactérias e fungos. $\mathrm{O}$ delineamento experimental adotado foi o de blocos ao acaso, em esquema de parcelas subdivididas, com quatro repetições. As parcelas foram constituídas pelos sistemas (monocultura e silvipastoril) e, as subparcelas, por seis épocas de avaliação $(30,60$, 90, 120, 150 e 180 dias). Houve diferenças significativas para as variáveis estudadas entre os solos das áreas de pastagens em sistemas de monocultura e silvipastoril. O solo sob silvipastoril apresentou valores superiores ao da monocultura para o conteúdo de Cmic, $\mathrm{C}_{\mathrm{org}}$ e $\mathrm{CO}_{2}$. A comunidade bacteriana proporcionou maiores valores de decomposição para a palha de capim no sistema de silvipastoril. Os menores valores foram observados para a decomposição da palhada pela comunidade fúngica. Os resultados indicam que o sistema silvipastoril favorece a biomassa e atividade microbiana do solo. Além disso, a atividade decompositora é acelerada neste sistema.

Palavras-chave: Decomposição, indicadores biológicos, matéria orgânica do solo

\begin{abstract}
Microbial biomass is an important soil component which contributes to maintaining the ecosystem of pastures, mainly in tropical soils. Therefore, the objective was to evaluate soil microbial biomass and activity in pasture systems under monoculture of Brachiaria brizantha cv. Marandu, and silvopastoral system composed of grass and coconut (Cocos nucifera). The experiment was conducted in 2009, the period from May to November 2009 in an experimental field of Embrapa Mid-North in Parnaíba-PI. It was evaluated soil fertility, soil organic carbon $\left(\mathrm{C}_{\text {org }}\right)$, soil microbial biomass $\left(\mathrm{C}_{\text {mic }}\right)$, soil respiration

${ }^{1}$ D.Sc., Prof. da Universidade Estadual do Piauí, Campus de Picos, UESPI, Picos, PI. E-mail: gynnaazar@yahoo.com.br

${ }^{2}$ D.Sc., Prof. da Universidade Federal do Piauí , UFPI, Centro de Ciências Agrárias, Laboratório de Qualidade do Solo, Campus da Socopo, Teresina, PI. Bolsista do CNPq. E-mail: asfaruaj@yahoo.com.br

${ }^{3}$ D.Sc., Prof. do Dept ${ }^{\circ}$ de Zootecnia UFPI, Centro de Ciências Agrárias, Campus da Socopo, Teresina, PI. E-mail: maeliz@uol.com

${ }^{4}$ D.Sc., Pesquisadora da Embrapa Meio Norte, Teresina, PI. E-mail: danielle.azevedo@embrapa.br
\end{abstract}

* Autor para correspondência 
$\left(\mathrm{CO}_{2}\right)$, and decomposition activity of bacteria and fungi. The experimental design was a randomized block in split plot with four replications. The plots consisted of systems (monoculture and silvopastoral) and subplots, six times (30,60, 90, 120, 150 and 180 days). There were significant differences for the variables studied between the soils of areas of monoculture and silvopastoral systems. The soil under silvopastoral showed values higher than those in monoculture for $\mathrm{C}_{\text {mic }}, \mathrm{C}_{\text {org }}$ and $\mathrm{CO}_{2}$ content. The bacterial community promoted higher values of decomposition for the straw of grass in a silvopastoral system. The lowest values were observed for the decomposition of straw by fungal community. The results indicate that the silvopastoral system favors soil microbial biomass and activity. Moreover, the decomposition is accelerated activity in this system.

Key words: Decomposition, biological indicators, soil organic matter

\section{Introdução}

A exploração convencional de pasto atualmente não atende mais às exigências dos produtores, em relação à produtividade, e tem ocasionando degradação do solo. Uma saída para diminuir a degradação do solo causada pela exploração convencional de pasto é a utilização do sistema silvipastoril (SSP). Este sistema corresponde a uma modalidade dos sistemas agroflorestais (SAFs), sendo aquele caracterizado pela combinação de cultivos florestais e criação de animais numa mesma área, de forma simultânea ou escalonada no tempo (PALM et al., 2007).

Os SSP apresentam características que contribuem para manutenção ou a melhoria dos atributos químicos e físicos do solo (ALBRECHT; KANDJI, 2003), ao mesmo tempo em que beneficia os processos biológicos (CARDOSO; KYUPER, 2006). A utilização de diferentes espécies, nesse tipo de sistema, favorece uma melhor exploração do solo pelo efeito das raízes além do aumento na quantidade de serrapilheira depositada. A serrapilheira constitui-se na camada de detritos vegetais (folhas, ramos, caules, cascas, frutos, flores) disposta na superfície do solo (BORÉM; RAMOS, 2002), e sua produção seguida da decomposição, representa o principal meio de transferência de $\mathrm{C}$ orgânico e da maior parte dos macro e micronutrientes para o solo, possibilitando a sua reabsorção pelos vegetais (SCHUMACHER et al., 2004).

O processo de decomposição de resíduos vegetais é influenciado, principalmente, pela qualidade do substrato (SMITH; BRADFORD, 2003) relacionado com as quantidades de carbono e nitrogênio (relação C/N) (ARAÚJO; MELO, 2010). Por outro lado, a biomassa microbiana do solo tem papel fundamental no processo (BROOKES, 2001). A biomassa microbiana é definida como o componente vivo da matéria orgânica do solo excluindo-se a macrofauna e as raízes das plantas (BROOKES, 2001). A biomassa microbiana é um dos componentes que controlam funções chaves no solo, como a decomposição e o acúmulo de matéria orgânica, ou transformações envolvendo os nutrientes minerais (ARAÚJO; MONTEIRO, 2007). Desta forma, a biomassa pode atuar diretamente na decomposição e na dinâmica da serrapilheira. Objetivou-se com este trabalho avaliar a biomassa e atividade microbiana do solo sob pastagem em sistema de monocultura e silvipastoril.

\section{Material e Métodos}

O trabalho foi conduzido no Campo Experimental da Embrapa Meio Norte/UEP Parnaíba, no município de Parnaíba-PI (254'18,89” S e 41 46'33,24" O) no período de maio a novembro de 2009. A classificação climática da região é do tipo sub-úmido seco e tipo úmido, nos períodos regular e chuvoso, respectivamente. Os dados climáticos correspondentes ao período do experimento foram obtidos em estação meteorológica localizada na própria Embrapa (Figuras 1 e 2). 
Figura 1. Variação da média mensal de temperatura durante o período do experimento.

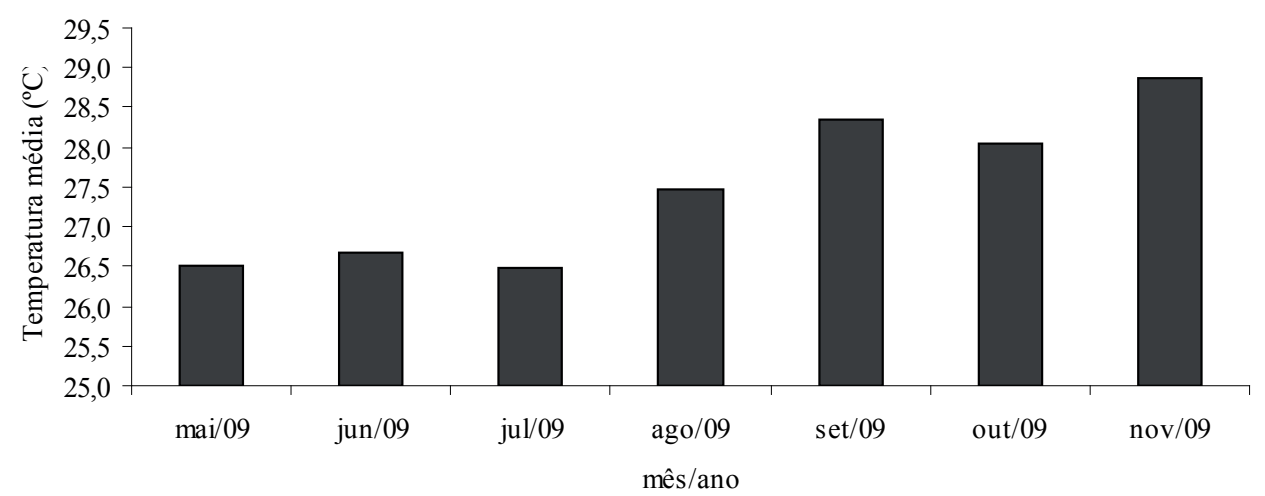

Fonte: Elaboração dos autores.

Figura 2. Variação da média mensal de precipitação pluvial durante o período do experimento.

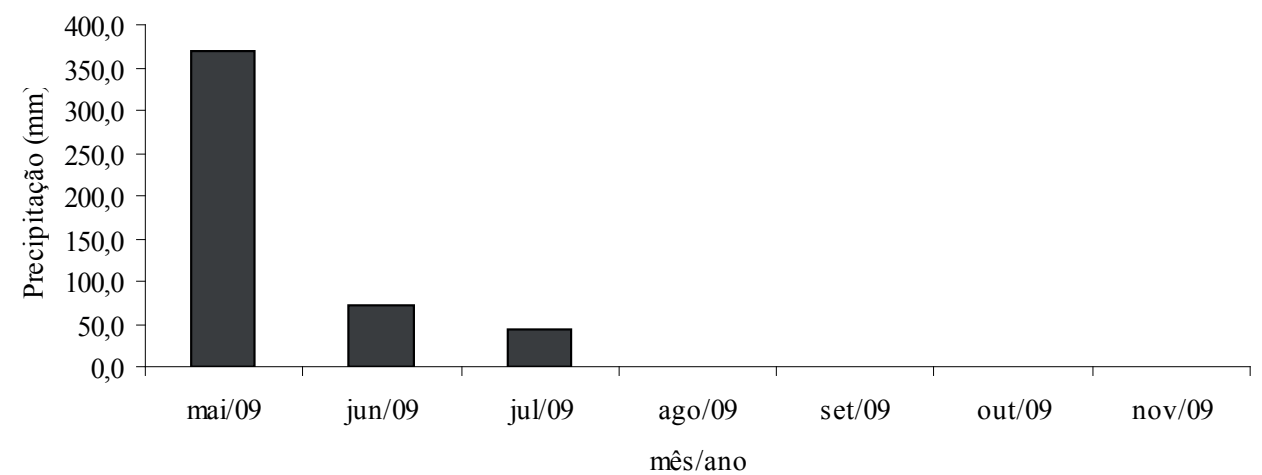

Fonte: Elaboração dos autores.

Amostras de solo na profundidade de $0-20 \mathrm{~cm}$ foram coletadas antes da instalação do experimento e submetidas à análise química (TEDESCO; GIANELLO; BISSANI, 1995), sendo realizada também a análise granulométrica, pelo método da Pipeta, no Laboratório de Solo e Água da UFPI (Tabela 1). O solo das duas áreas apresentou textura franco arenosa, com mais de $80 \%$ de areia, com $\mathrm{pH}$ revelando acidez moderada, não necessitando de calagem, e pobre em P, K e N. Com base nestes resultados procedeu-se adubação de fundação com $70 \mathrm{~kg}$ de $\mathrm{P}_{2} \mathrm{O}_{5} /$ ha com o plantio do capim, realizado em fevereiro de 2008 . Um mês após o plantio procedeu-se adubação de cobertura com 60 $\mathrm{kg}$ de $\mathrm{K}_{2} \mathrm{O}$ ha $^{-1}$ e $100 \mathrm{~kg}$ de $\mathrm{N} \mathrm{ha}^{-1}$. As áreas foram adubadas com 500 e $60 \mathrm{~kg}$ de $\mathrm{N}_{\text {e }} \mathrm{K}_{2} \mathrm{O}$ por ano $\mathrm{ha}^{-1}$, nas formas de uréia e $\mathrm{KCl}$ respectivamente, distribuídos em cada piquete após cada ciclo de pastejo.

$\mathrm{O}$ experimento foi implantado numa área de aproximadamente 2,82 ha de pasto de Brachiaria brizantha $\mathrm{cv}$. Marandu, sendo 1,41 ha de silvipastoril entre pasto e coqueiros (Cocos nucifera) e 1,41 ha em monocultura. O sistema silvipastoril foi implantado, em 2008, com a semeadura do capim em áreas de coqueiros adultos, espaçados entre si em 7 m. Cada uma destas áreas foi subdividida em dez piquetes, com períodos de ocupação e descanso de três dias e 27 dias, respectivamente. Foram utilizadas vacas da raça Girolando, em taxa de lotação de 3 unidade animal (UA)/ha que produzem aproximadamente $75 \mathrm{~kg}$ de esterco dia $^{-1}$. As áreas foram adubadas com $500 \mathrm{~kg}$ de $\mathrm{N} \mathrm{ha}^{-1}$ ano $^{-}$ 1, na forma de uréia, distribuídos após cada ciclo 
de pastejo. No período seco, caracterizado pelos meses de julho a novembro, adotou-se a irrigação por baixa pressão, com turno de rega de no mínimo cinco horas e intervalo de três dias. Cada uma dessas áreas correspondeu a um tratamento: Sistema de Monocultura (Mon) e Sistema Silvipastoril (SSP).

Tabela 1. Características químicas e físicas de amostras de solo, coletadas na profundidade de 0-20 cm sob de 0-20 $\mathrm{cm}$ sob sistemas de monocultura (Mon) e silvipastoril (SSP).

\begin{tabular}{|c|c|c|c|c|c|c|c|c|c|c|c|}
\hline Sistemas & $\mathrm{pH}$ & $\mathrm{P}$ & $\mathrm{K}$ & $\mathrm{Ca}^{2+}$ & $\mathrm{Mg}^{2+}$ & $\mathrm{Na}$ & $\mathrm{Al}^{3+}$ & $\mathrm{H}+\mathrm{Al}$ & CTC & $\mathrm{V}$ & $\mathrm{m}$ \\
\hline & $\mathrm{H}_{2} \mathrm{O}$ & $\mathrm{mg} / \mathrm{dm}^{3}$ & \multicolumn{7}{|c|}{---------------------------cmol//dm³ } & \multicolumn{2}{|c|}{-----\%"---- } \\
\hline Mon & 6,1 & 5,8 & 0,1 & 1,9 & 0,7 & 0,03 & 0,02 & 1,2 & 3,9 & 69,0 & 0,7 \\
\hline \multirow[t]{2}{*}{ SSP } & 6,1 & 5,2 & 0,2 & 1,3 & 0,8 & 0,02 & 0,02 & 1,1 & 3,4 & 68,8 & 0,9 \\
\hline & \multicolumn{2}{|c|}{ Areia grossa } & \multicolumn{2}{|c|}{ Areia fina } & \multicolumn{2}{|c|}{ Silte } & \multicolumn{2}{|c|}{ Argila } & \multicolumn{3}{|c|}{ Classificação textural } \\
\hline Mon & \multicolumn{2}{|c|}{47,0} & \multicolumn{2}{|c|}{40,9} & \multicolumn{2}{|c|}{3,6} & \multicolumn{2}{|c|}{8,6} & \multicolumn{3}{|c|}{ areia franca } \\
\hline SSP & \multicolumn{2}{|c|}{48,1} & \multicolumn{2}{|c|}{40,0} & \multicolumn{2}{|c|}{3,3} & \multicolumn{2}{|c|}{8,6} & \multicolumn{3}{|c|}{ areia franca } \\
\hline
\end{tabular}

Fonte: Elaboração dos autores.

O delineamento experimental adotado foi o de blocos ao acaso, em esquema de parcelas subdivididas no tempo, com quatro repetições. As parcelas foram constituídas pelos sistemas (monocultura e silvipastoril) e, as subparcelas, por seis épocas de avaliação (30, 60, 90, 120, 150 e 180 dias).

Foram coletadas cinco amostras compostas de solo, em cada tratamento, sendo cada uma, formada por seis amostras simples coletadas aleatoriamente de forma representativa de toda a área, na profundidade, 0-10 cm, em cada época de amostragem do experimento. Posteriormente, essas amostras foram secas ao ar e peneiradas em peneiras com malha de $2 \mathrm{~mm}$ (TFSA), para realização das análises químicas do solo, determinou-se o $\mathrm{pH}$ em água (relação solo:solução 1:2:5) e os teores de $\mathrm{P}$, $\mathrm{Ca}^{2+}, \mathrm{Mg}^{2+}, \mathrm{K}^{+}$e $\mathrm{Al}^{3+}$ seguindo a metodologia de Tedesco, Gianello e Bissani (1995).

Em cada período foram avaliados os teores de $\mathrm{P}, \mathrm{Ca}, \mathrm{Mg}, \mathrm{K}$ e matéria orgânica (TEDESCO; GIANELLO; BISSANI, 1995). Em relação a atributos biológicos foram avaliados o $\mathrm{C}$ microbiano $\left(\mathrm{C}_{\text {mic }}\right)$, respiração do solo $\left(\mathrm{CO}_{2}\right)$, quociente microbiano $\left(\mathrm{q}_{\text {mic }}\right)$ e a atividade decompositora. Para estas avaliações foram amostrados quatro pontos em uma área de $1 \mathrm{~m}^{2}$ na profundidade de $0-10 \mathrm{~cm}$, nos dois sistemas.

$\mathrm{O} \mathrm{C}_{\text {org }}$ foi determinado por oxidação da matéria orgânica com dicromato de potássio na presença de ácido sulfúrico concentrado (Walkley-Black) e titulação com sulfato ferroso amoniacal. $\mathrm{O} \mathrm{C}_{\text {mic }}$ foi determinado pelo método da irradiação-extração, utilizando na eliminação dos microrganismos em um forno de microondas com frequência de microondas de $2.450 \mathrm{MHz}$ e energia a $900 \mathrm{~W}$ por 180s (FERREIRA; CAMARGO; VIDOR, 1999). A respiração basal foi determinada pela quantificação do $\mathrm{CO}_{2}$, conforme Alef (1995), através da titulação do hidróxido de sódio por ácido clorídrico. O quociente microbiano $\left(\mathrm{q}_{\text {mic }}\right)$ foi calculado de acordo com Sparling (1992). As avaliações foram realizadas sempre dois dias após a coleta do solo em cada período.

Para avaliação da atividade decompositora foram utilizadas bolsas de tela de polietileno (litter bags) (THOMAS; ASAKAWA, 1993), com dimensões de $0,2 \times 0,2 \mathrm{~m}$ e malha de $0,1 \mathrm{~mm}$, que foram preenchidas com resíduos culturais da palha de coqueiro e do capim com massas e composições químicas conhecidas (Tabela 2), e enterradas na profundidade de 0-10 $\mathrm{cm}$ nos dois sistemas. As amostragens das 
bolsas foram realizadas em intervalos regulares de 30 dias, durante 180 dias. Após cada período de amostragem, os resíduos vegetais remanescentes nas bolsas foram secos a $65^{\circ} \mathrm{C}$ em estufa com circulação forçada de ar até peso constante, para a determinação da matéria seca remanescente (MSR).

Tabela 2. Composição química em percentagens de matéria seca (MS), proteína bruta (PB), fibra em detergente neutro (FDN), fibra em detergente ácido (FDA), hemicelulose (HEM) e matéria orgânica (MO) da palha do coqueiro e do capim.

\begin{tabular}{lcccccc}
\hline Resíduo & MS & PB & FDN & FDA & HEM & MO \\
\hline & \multicolumn{7}{c}{$\%$} & $\%$ & & \\
\hline Palha do coqueiro & 93,2 & 7,6 & 59,9 & 52,3 & 7,5 & 92,9 \\
Capim & 92,6 & 7,6 & 72,7 & 45,6 & 27,1 & 93,6 \\
\hline
\end{tabular}

Fonte: Elaboração dos autores.

Os dados foram testados para a normalidade e homogeneidade de variâncias dos efeitos principais (coberturas e épocas de avaliação) e da sua interação. Quando a interação se mostrou significativa, procederam-se aos desdobramentos necessários, de acordo com Banzatto e Kronka (2006). As médias dos atributos avaliados foram comparadas entre si em cada época de amostragem, pelo teste de Tukey a 5\% e ajustado por regressão polinomial.

\section{Resultados e Discussão}

Os teores de $\mathrm{P}, \mathrm{K}, \mathrm{Ca}$ e $\mathrm{Mg}$, de modo geral, não apresentaram diferenças em relação aos sistemas e tempos de avaliação (Tabela 3). Com estes resultados pode-se afirmar que à adubação mineral realizada antes do início do experimento apresentou resultados satisfatórios com uniformização dos teores de nutrientes. Os teores de $\mathrm{P}, \mathrm{K}, \mathrm{Ca}$ e $\mathrm{Mg}$ encontram-se dentro da faixa adequada de nutrientes conforme Novais et al. (2007).

Tabela 3. Características químicas do solo, em amostras coletadas na profundidade de $0-10 \mathrm{~cm}$ sob sistemas de monocultura (Mon) e silvipastoril (SSP) em diferentes tempos (dias) de amostragem.

\begin{tabular}{|c|c|c|c|c|c|c|}
\hline \multirow{2}{*}{ Sistemas } & \multicolumn{6}{|c|}{ Tempo (dias) } \\
\hline & 30 & 60 & 90 & 120 & 150 & 180 \\
\hline & \multicolumn{6}{|c|}{--------P (mg/dm³) --------- } \\
\hline Mon & 19,9 & 22,3 & 21,4 & 17,4 & 14,5 & 17,9 \\
\hline \multirow{2}{*}{ SSP } & 12,8 & 13,6 & 18,0 & 24,6 & 22,0 & 11,3 \\
\hline & \multicolumn{6}{|c|}{ 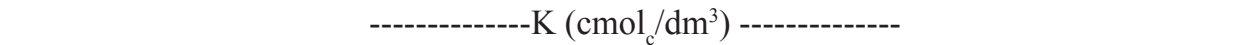 } \\
\hline Mon & 0,1 & 0,2 & 0,2 & 0,2 & 0,2 & 0,4 \\
\hline \multirow{2}{*}{ SSP } & 0,1 & 0,2 & 0,1 & 0,1 & 0,3 & 0,2 \\
\hline & \multicolumn{6}{|c|}{ 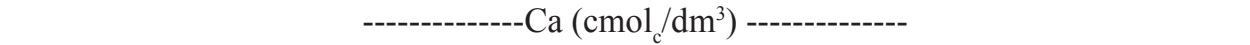 } \\
\hline Mon & 1,2 & 1,5 & 1,5 & 1,4 & 1,4 & 1,3 \\
\hline \multirow[t]{2}{*}{ SSP } & 1,4 & 1,4 & 1,3 & 1,3 & 1,6 & 1,3 \\
\hline & \multicolumn{6}{|c|}{------Mg $\left(\mathrm{cmol}_{\mathrm{c}} / \mathrm{dm}^{3}\right)$--- } \\
\hline Mon & 0,6 & 0,7 & 0,5 & 0,4 & 0,6 & 0,6 \\
\hline SSP & 0,6 & 0,6 & 0,5 & 0,6 & 0,6 & 0,6 \\
\hline
\end{tabular}

Fonte: Elaboração dos autores. 
Os dados referentes ao $\mathrm{C}_{\text {mic }}, \mathrm{C}_{\text {org }}, \mathrm{q}_{\text {mic }}$ e $\mathrm{CO}_{2}$ estão apresentados na Figura 3. Houve diferenças significativas para estas variáveis entre os solos das áreas de pastagens em sistemas de monocultura e silvipastoril. Independentemente do período avaliado, observou-se que os maiores valores de $\mathrm{C}_{\text {mic }}$ foram obtidos na pastagem em sistema silvipastoril.

Figura 3. Teores de $\mathrm{C}$ microbiano $\left(\mathrm{mg} \mathrm{kg}^{-1}\right), \mathrm{C}$ orgânico $\left(\mathrm{g} \mathrm{kg}^{-1}\right)$, quociente microbiano (\%) e respiração basal (mg $\left.\mathrm{CO}_{2} \mathrm{~kg}^{-1} \mathrm{dia}^{-1}\right)$ do solo das áreas de pastagem em sistemas de monocultura (\$) e silvipastoril (घ) durante 180 dias.
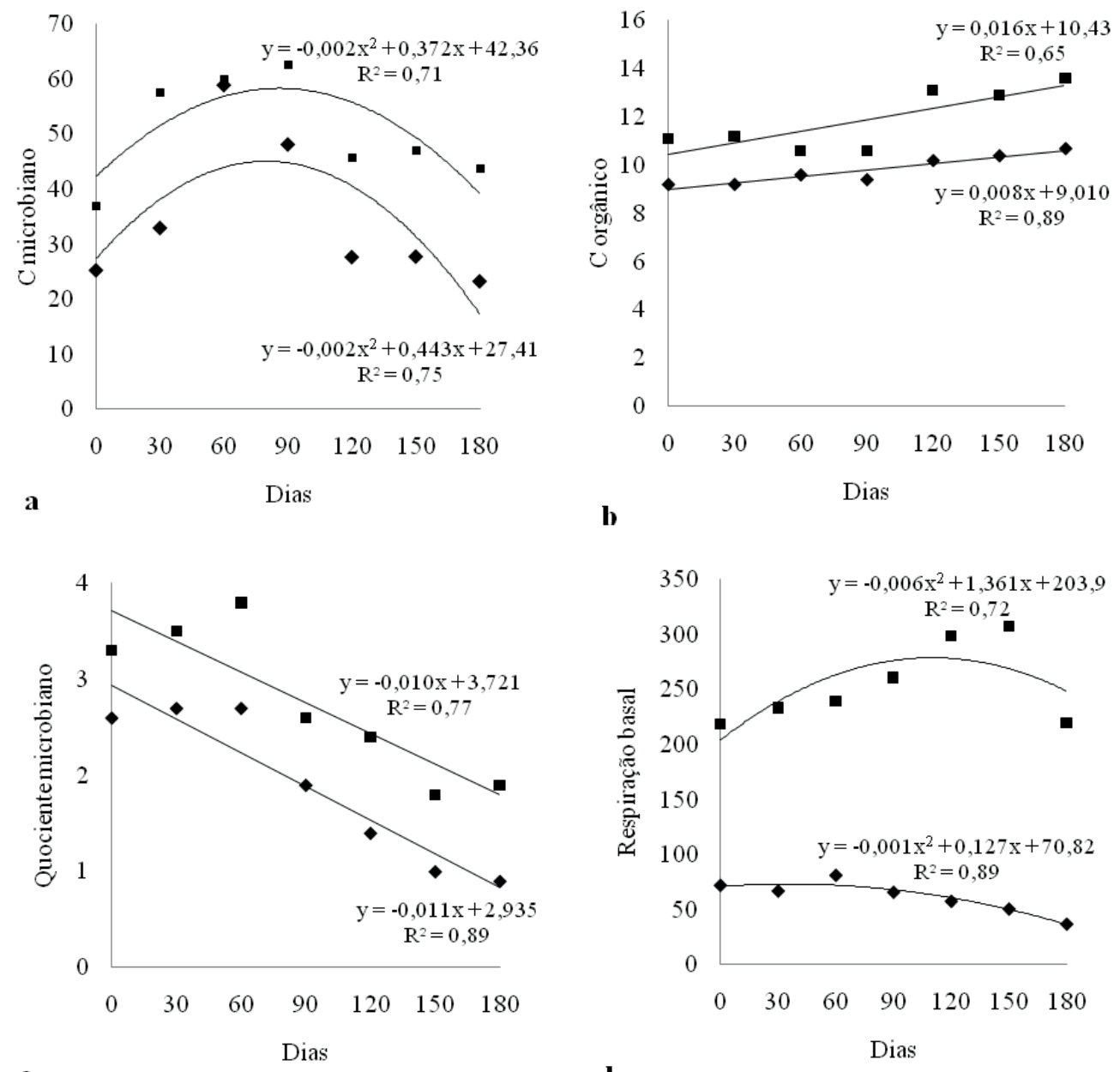

c

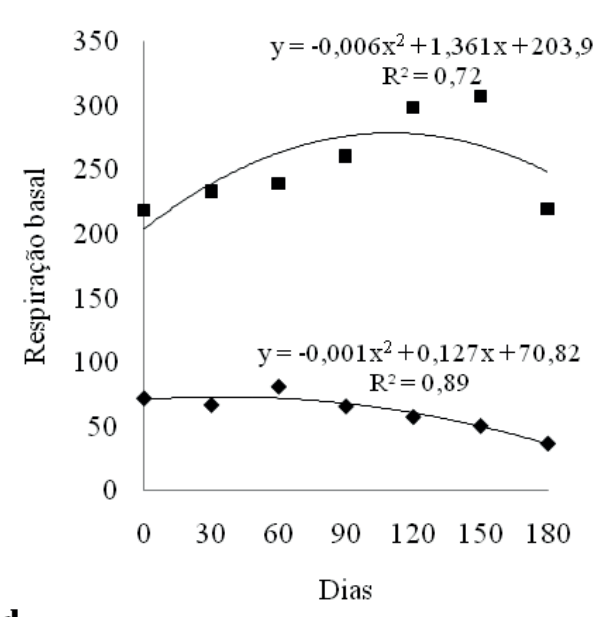

Fonte: Elaboração dos autores.

Estes resultados se devem, principalmente, à contribuição da serrapilheira do coqueiro associado ao capim Brachiaria. Além disso, a rizosfera das duas culturas pode ter contribuído pela maior disponibilidade de substratos orgânicos para a microbiota do solo (OLIVEIRA; MENDES; VIVALDI, 2001). Resultados semelhantes foram observados por Maia et al. (2006) avaliando atributos biológicos do solo em SAFs e pastagens consorciadas.

Por outro lado, a presença do coqueiro associado à presença de cobertura morta, oriunda da serrapilheira das duas culturas, proporciona melhora no microclima do solo e favorece a biomassa microbiana. Sampaio, Araújo e Santos 
(2008) estudaram a biomassa microbiana nas linhas e entrelinhas de acerola e goiaba e observaram maiores valores de $\mathrm{C}_{\text {mic }}$ sob as copas das plantas, o que indica que o sombreamento, associado à presença de composto orgânico, contribui para o aumento da biomassa microbiana.

Os teores de $\mathrm{C}_{\text {mic }}$ variaram entre as épocas avaliadas, isto é, houve efeito de tempo de amostragem. Os menores valores foram obtidos aos 180 e 0 dias para a monocultura e para o silvipastoril com 23,15 e 36,98 $\mathrm{mg} \mathrm{C} \mathrm{kg}^{-1}$ de solo, respectivamente. Já os maiores valores foram observados aos 60 e 90 dias para a monocultura e o silvipastoril com teores 58,94 e $62,56 \mathrm{mg} \mathrm{C} \mathrm{kg}^{-1} \mathrm{de}$ solo, respectivamente. Aos 60 e 90 dias houve uma combinação de condições climáticas favoráveis a microbiota do solo, uma vez que aos 60 dias apesar de apresentar ainda precipitação (baixa) iniciou-se a irrigação com uma maior disponibilidade de água, que combinado com a temperatura favoreceu a biomassa microbiana do solo.

O solo sob sistema silvipastoril apresentou valores superiores ao da monocultura para o conteúdo de $\mathrm{C}_{\text {org }}$. Os dados mostram que há um aumento significativo no conteúdo de carbono orgânico ao longo do tempo. Isto é devido ao aporte permanente de serrapilheira proveniente do capim Marandu associada ao coqueiro no silvipastoril que contribui para o aumento no conteúdo de $\mathrm{C}_{\text {org }}$. Segundo Leite et al. (2010), os resíduos orgânicos depositados no solo são essenciais no processo de adição de carbono orgânico ao longo do tempo. O aumento de carbono orgânico é importante para a sustentabilidade do sistema, pela influência da matéria orgânica nas propriedades físicas, químicas e biológicas do solo (SPARLING, 1997).

Os valores de $\mathrm{q}_{\text {mic }}$ foram maiores na área sob silvipastoril do que na monocultura. Os solos das áreas sob silvipastoril e monocultura apresentaram valores máximos de $\mathrm{q}_{\text {mic }}$ de 3,75 e 2,72\%, respectivamente. Estes valores de $\mathrm{q}_{\text {mic }}$ estão dentro da proporção de 1 a $4 \%$ da biomassa microbiana no conteúdo de carbono orgânico (SPARLING, 1992). Entretanto, os maiores valores observados no solo sob silvipastoril indicam que este sistema é mais sustentável, uma vez que o $\mathrm{q}_{\text {mic }}$ tem sido usado como indicador de sustentabilidade de ecossistemas (POWLSON; BROOKES; CHRISTENSES, 1987).

Com o passar do tempo houve um decréscimo na percentagem de $\mathrm{q}_{\text {mic }}$ nos dois sistemas sugerindo que o $\mathrm{C}_{\text {org }}$ encontra-se indisponível para microbiota do solo, ou seja, o C que estava na forma microbiana (instável) foi convertido para formas orgânicas $\mathrm{C}_{\text {org }}$ (estáveis) (ANDERSON; DOMSCH, 1989). Segundo Sampaio, Araújo e Santos (2008) valores altos de $\mathrm{q}_{\text {mic }}$ indicam uma matéria orgânica muito ativa e sujeita às transformações, então, com os valores apresentados neste trabalho, sugere-se que houve uma diminuição na transformação da matéria orgânica.

Os valores de respiração do solo foram maiores na área sob silvipastoril do que na monocultura em todos os períodos de avaliação. Os maiores valores da respiração em sistemas com pastagens consorciadas com coqueiro pode ser devido à grande quantidade de serrapilheira sob essas coberturas vegetais, que proporciona a presença de matéria orgânica com grandes quantidades de carbono prontamente disponível (SILVA et al., 2010), pois a respiração do solo pode atingir um valor quatro vezes maior em ecossistemas com pastagens consorciadas do que em monocultura (ASSIS JUNIOR et al., 2003). Este aumento na respiração do solo foi confirmado por Della Bruna et al. (1991) que mostraram que a adição de serrapilheira pode aumentar cerca de cinco vezes a atividade biológica nos solos, sendo o aumento da atividade microbiana uma característica desejável, já que pode significar rápida transformação de resíduos orgânicos em nutrientes para as plantas (TU; RISTAINO; HU, 2006).

O padrão de decomposição da palha de capim e do coco apresentou variação de acordo com o sistema avaliado (Figura 4). 
Figura 4. Decomposição do capim (C) e palha de coco (P) em pastagens em monocultura (Mon) e silvopastoril (SSP)

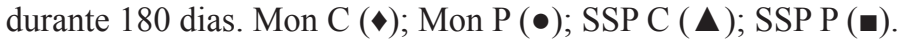

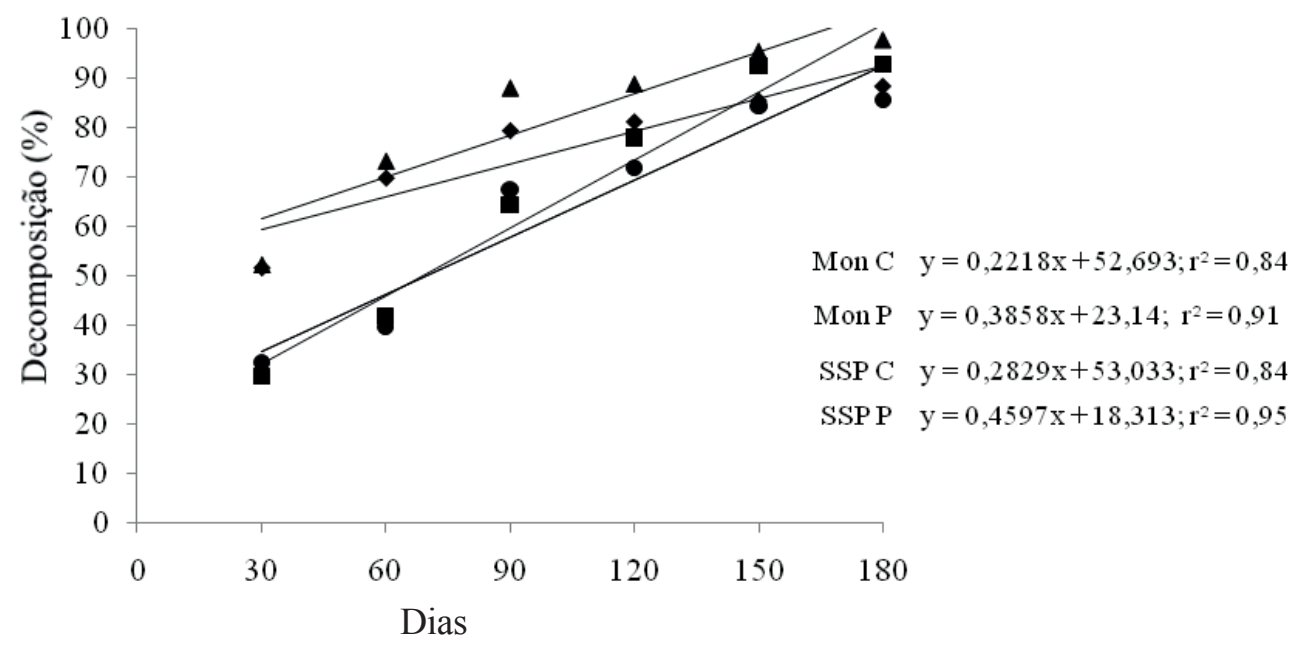

Fonte: Elaboração dos autores.

Houve maior decomposição inicial do capim, nos dois sistemas, do que da palha. Entretanto, ao final do período de avaliação, os valores de decomposição foram semelhantes nos dois tipos de resíduos. A maior decomposição do capim se deu em virtude da composição do resíduo o que influencia na velocidade de decomposição. Resultados semelhantes foram reportados por Torres e Pereira (2008) que observaram que o capim Brachiaria apresentou maiores valores de decomposição do que o milheto em virtude da sua composição.

Por outro lado, a decomposição foi maior, significativamente, no SSP do que no MON para os dois resíduos. Este resultado indica que no SSP a maior quantidade de biomassa microbiana favoreceu o aumento da decomposição, uma vez que a microbiota do solo é a principal responsável pelo processo.

Diante dos resultados concluem que o sistema silvipastoril, por suas características, contribuiu para aumentar o conteúdo de $\mathrm{C}$ orgânico e microbiano no solo do que a monocultura. Além disso, a atividade decompositora é maior no sistema silvipastoril.

\section{Agradecimentos}

A Embrapa Meio-Norte pela disponibilidade do espaço físico e apoio logístico à realização desse projeto. A Fundação de Amparo a Pesquisa dos Estados do Maranhão (FAPEMA) pela concessão de bolsa de doutorado à primeira autora. Ao $\mathrm{CNPq}$ pela concessão da Bolsa de Produtividade de Pesquisa à Ademir S. F. Araújo.

\section{Referências}

ALBRECHT, A.; KANDJI, S. T. Carbon sequestration in tropical agroforestry systems. Agriculture, Ecosystem and Environment, Amsterdam, v. 99, n. 1, p. 15-27, 2003.

ALEF, K. Soil respiration. In: ALEF, K.; NANNIPIERI, P. (Ed.). Methods in applied soil microbiology and biochemistry. London: Academic Press, 1995. p. 214219.

ANDERSON, T. H.; DOMSCH, K. H. Ratio of microbial biomass carbon to total organic carbon in arable soils. Soil Biology and Biochemistry, Oxford, v. 21, n. 3, p. 471-479, 1989.

ARAÚJO, A. S. F.; MELO, W. J. Soil microbial biomass in organic farming system. Ciência Rural, Santa Maria, v. 40, n. 12 , p. 2419-2426, 2010.

ARAÚJO, A. S. F.; MONTEIRO, R. T. R. Indicadores biológicos de qualidade do solo. Bioscience Journal, 
Uberlândia, v. 23, n. 1, p. 66-75, 2007.

ASSIS JÚNIOR, S. L.; ZANUNCIO, J. C.; KASUYA, M. C. M.; COUTO, L.; MELIDO, R. C. N. Atividade microbiana do solo em sistemas agroflorestais, monoculturas, mata natural e área desmatada. Revista Árvore, Viçosa, v. 27, n. 1, p. 35-41, 2003.

BANZATTO, D. A.; KRONKA, S. N. Experimentação agrícola. 4. ed. Jabotical: FUNEP, 2006.

BORÉM, R. A. T.; RAMOS, D. P. Variação estacional e topográfica de nutrientes na serapilheira de um fragmento de mata atlântica. Cerne, Viçosa, v. 8, n. 2, p. 42-59, 2002.

BROOKES, P. C. The soil microbial biomass: concept, measurement and applications in soil ecosystem research. Applid Environmental and Microbiology, New York, v. 16, n. 1, p. 131-140. 2001.

CARDOSO, M. I.; KUYPER, T. W. Mycorrhizas and tropical soil fertility. Agriculture, Ecosystem and Environment, Amsterdam, v. 116, n. 1, p. 72-84, 2006.

DELLA BRUNA, E.; BORGES, A. C.; FERNANDES, B.; BARROS, N. F.; MUCHOVEJ, R. M. C. Atividade da microbiota de solos adicionados de serrapilheira de eucalipto e de nutrientes. Revista Brasileira de Ciência do Solo, Viçosa, MG, v. 15, n. 1, p. 15-20, 1991.

FERREIRA, A. S.; CAMARGO, F. A. O.; VIDOR, C. Utilização de microondas na avaliação da biomassa microbiana do solo. Revista Brasileira de Ciência do Solo, Viçosa, MG, v. 23, n. 6, p. 991-996, 1999.

LEITE, L. F. C.; FREITAS, R. C. A.; SAGRILO, E.; GALVÃO, S. R. S. Decomposição e liberação de nutrientes de resíduos vegetais depositados sobre Latossolo Amarelo no Cerrado Maranhense. Revista Ciência Agronômica, Fortaleza, v. 41, n. 1, p. 29-35, 2010.

MAIA, S. M. F.; XAVIER, F. A. S.; OLIVEIRA, T. S.; MENDONÇA, E. S.; ARAÚJO FILHO, J. A. Impactos de sistemas agroflorestais e convencional sobre a qualidade do solo no semi-árido cearense. Revista Árvore, Viçosa, v. 30, n. 4, p. 837-848, 2006.

NOVAIS, R. F.; ALVAREZ, V. H.; BARROS, N. F.; FONTES, R. L. F.; CANTARUTTI, R. B.; NEVES, J. C. L. Fertilidade do solo. Viçosa, MG: Sociedade Brasileira de Ciência do Solo, 2007.

OLIVEIRA, J. R. A.; MENDES, I. C.; VIVALDI, L. Carbono da biomassa microbiana em solos de cerrado sob vegetação nativa e sob cultivo: avaliação dos métodos fumigação-incubação e fumigação-extração. Revista Brasileira de Ciência do Solo, Viçosa, MG, v. 25, n. 5, p. 863-871, 2001.
PALM, J. H. N.; GRAVES, A. R.; BUNCE, R. G. H.; BURGESS, P. J. Modeling environmental benefits of silvoarable agroforestry in Europe. Agriculture, Ecosystem and Environment, Amsterdam, v. 119, n. 3, p. 320-334, 2007.

POWLSON, D. S.; BROOKES, P. C.; CHRISTENSES, B. T. Measuring of soil microbial biomass provides an early indication of changes in total soil organic matter due to straw incorporation. Soil Biology and Biochemistry, Oxford, v. 19, n. 1, p. 159-164. 1987.

SAMPAIO, D. B.; ARAÚJO, A. S. F.; SANTOS, V. B. Avaliação de indicadores biológicos de qualidade do solo sob sistemas de cultivo convencional e orgânico de frutas. Ciência e Agrotecnologia, Lavras, v. 32, n. 2, p. 353-359, 2008.

SCHUMACHER, M. V.; BRUN, E. J.; HERNANDES, J. I.; KÖNIG, F. G. Produção de serapilheira em uma floresta de Araucaria angustifolia (bertol.) Kuntze no município de Pinhal Grande-RS. Revista Árvore, Viçosa, v. 28, n. 1, p. 29-37, 2004.

SILVA, R. C.; PEREIRA, J. M.; ARAÚJO, Q. R.; PIRES, J. V.; REI, A. J. Alterações nas propriedades físicas e químicas de um Chernossolo com diferentes coberturas vegetais. Revista Brasileira de Ciência do Solo, Viçosa, MG, v. 31, n. 1, p. 101-107, 2007.

SMITH, V. C.; BRADFORD, M. A. Litter quality impacts on grassland litter decomposition are differently dependent on soil fauna across time. Applied Soil Ecology, Amsterdam, v. 24, n. 2, p. 197-203, 2003.

SPARLING, G. P. Ratio of microbial biomass carbon to soil organic carbon as a sensitive indicator of changes in soil organic matter. Australian Journal of Soil Research, Victoria, v. 30, n. 2, p. 195-207, 1992.

Soil microbial biomass, activity and nutrient cycling as indicators of soil health. In: PANKHURST, C. E.; DOUBE, B. M.; GUPTA, V. V. S. R. (Ed.). Biological indicators of soil health. CAB International: Wallingford, 1997. p. 97-119.

TEDESCO, M. J.; GIANELlO, C.; BISSANI, C. A. Analises de solos, plantas e outros materiais. UFRGS: Porto Alegre; 1995. 230 p.

THOMAS, R. J.; ASAKAWA, N. M. Decomposition of leaf litter from tropical forage grasses and legumes. Soil Biology and Biochemistry, Oxford, v. 25, n. 10, p. 13511361, 1993.

TORRES, J. L. R.; PEREIRA, M. G. Dinâmica do potássio nos resíduos vegetais de plantas de cobertura no Cerrado. Revista Brasileira de Ciência do Solo, Viçosa, MG, v. 32, n. 9, p. 1609-1618, 2008. 
TU, C.; RISTAINO, J. B.; HU, S. Soil microbial biomass and activity in organic tomato farming systems: effects of organic inputs and straw mulching. Soil Biology and Biochemistry, Oxford, v. 38, n. 2, p. 247-255, 2006. 